\title{
Almost Ideal Demand System for Red Meat in Egypt by Using AIDS Model
}

[Samir Basilious Nakhla Ghobrail , Nouran Abd El Hamid Ibrahim Abd El Gawwad, Mamdouh Elbadry Mohamed]

\begin{abstract}
The problem of providing food from animal protein is great importance when the authors of productivity policy since it is one of the main and essential food ingredients for human nutrition and maintain his health, are obtained animal protein sources of red meat, white meat, fish, and is linked to the demand by increasing population, increasing per capita income and the level of health and nutrition of the population awareness and then increase the average per capita, with an average per capita red meat, fish and poultry in Egypt during the period (1990-2013) approximately $13.76,13.15,10.47 \mathrm{~kg} /$ year, while the annual growth rate of about $1.2 \%, 4.4 \%$, $2.33 \%$, respectively.
\end{abstract}

Results estimate the demand for red meat demand AIDS using the optimal model in the Arab Republic of Egypt during the period has shown (1990-2013):

1. High percentage of the Egyptian consumer spending on red meat, fish and poultry. Which amounted to about $58.8 \%$, $24.2 \% 0.17 \%$, respectively, which means the consumer preference for red meat for fish and poultry in bridging the requirements of the animal protein products.

2. The most important variables affecting the demand of red meat in Egypt is the average retail prices for red meat, fish and poultry, and spending on red meat.

3. Show of reference and the value of spending Elasticity (income demand) plants that red meat is a commodity, which means that the more consumer income spent, the more the ratio has increased to such item is greater than the rate of increase in the rate of income.

4. Show of reference and the value of demand elasticity coefficient Sarah- that the demand for red meat and fish is flexible, where the fall in response consumed quantity of these commodities to price changes, while showing that demand for poultry flexible, in terms of increased response to the amount consumed of these commodities to price changes.

1- Authors Name/ Samir Basilious Nakhla (Author)

line1: Institute of Agricultural Economic Research / Agricultural Research Center

line2: Egypt

2- Authors Name/ Nouran Abd El hamid (Author) line1: Agricultural College / Mansoura University line2: Egypt

3- Authors Name/ Mamdouh Elbadry Mohamed (Author) line1: Institute of Agricultural Economic Research / Agricultural Research Center line2: Egypt

\section{Recommendations:}

(A) Due to the high elasticity spending power of red meat should be the need for expansion in the production of red meat to ensure the availability prices to suit consumers with low incomes, as well as to encourage the breeding, production and fattening calves, and work on developing improved calves genetically and high productivity to ensure increased production of red meat.

(B) Encourage the provision of jam calves and feed them at affordable prices, leading to increased production of red meat, even lower production of which do not lead to higher domestic prices and the consequent decline of the average per capita

(C) Increasing the aquaculture to increase the fish production as one of the alternatives of red meat

Keywords - Almost Ideal Demand System (AIDS), Seemingly Unrelated Regression (SUR), Three Stage Least Square (3SLS), Generalized Method of Moments (GMM). Own Price Elasticity, Expenditure Elasticity, Cross Price Elasticity

\section{Introduction}

Agricultural sector is considered an important source to meet the population needs of the essential goods, and occupies the problem of providing animal protein food of particularly important when policy-makers productivity because it is one of the components of the major food necessary for the human nutrition and the maintenance of health, is access to sources of animal protein from red meat, white meat poultry and fish products. However Egypt is currently facing relatively high production costs of red meat and relatively high selling prices for consumers and a decrease in response to production and presentation for a considerable increase in demand, as needed to encourage greater domestic production of alternatives to red meat and thus increase domestic production of fish and poultry as alternatives. It is noted that expenditure on a particular commodity or group of certain food, heavily influenced by the level of total expenditure on the sets of goods and services.

The problem The red meat of staple food commodities that meet Egypt in the proportion of sufficiency was about $74.5 \%$ in 2013 , the quantities available for consumption of red meat about 1298 tons, while the average individual share was about $15.1 \mathrm{~kg} /$ year in 
2013, have reached an annual which increase rate of about $1.2 \%$ during the period (1990-2013). This shows that the high prices of red meat that makes the consumer to alternatives available in the markets where the average individual share was these alternatives were about 19.1 and $14.7 \mathrm{~kg} /$ year in 2013, while the annual growth rate was about $4.4 \%, 2.33 \%$ for fish and poultry, respectively during the period (1990-2013) table (1), figure (1).

The main objective of the research is estimating the best red meat demand in Egypt during the period (1990-2013) using Almost Ideal Demand System (AIDS), in order to identify the most important variables affecting the red meat based on the prices of red meat, fish and poultry, and analysis of the relationships between them on the light of competition in the percentage of their expenditure.

The research introduced (AIDS) to estimate of red meat demand during the period (1990-2013) using the method (Zellner), which had used the Stones Price Index.

The model of (AIDS) defined as:

$\mathbf{W}_{\mathrm{i}}=\boldsymbol{\alpha}_{\mathrm{i}}+\Sigma \gamma_{\mathrm{ij}} \operatorname{Ln} \mathbf{P}_{\mathbf{j}}+\boldsymbol{\beta}_{\mathrm{i}} \operatorname{Ln}(\mathbf{E} / \mathbf{P} *)$

Where:

$\mathbf{W}_{\mathbf{i}}$ : consumer expenditure on a commodity per $\mathrm{i}$ item.

$\boldsymbol{\alpha}_{\mathbf{i}}:$ constant term.

$\gamma_{\mathrm{ii}}, \boldsymbol{\beta}_{\mathrm{i}}:$ Parameters of the model.

$\mathbf{E}$ : total expenditure on commodity group in question.

$\mathbf{P}_{\mathbf{j}} \quad$ : current prices for a product $\mathrm{j}$ under consideration on the algorithm image.

$\mathbf{P} *$ : Number of Stones Price Index, calculated from the following equation:

$\operatorname{Ln} \mathbf{P}^{*}=\boldsymbol{\Sigma} \mathbf{W}_{\mathbf{i}} \operatorname{Ln} \mathbf{P}_{\mathbf{j}}$

This model is account on some important economic indicators, the demand elasticity's of price (Own), Cross and expenditure Elasticity. Where cannot estimate directly from the model (because the coefficients of the model's response rates for income and not quantity) and these elasticizes are:

\section{1 - Own Price Elasticity $\left(\varepsilon_{i i}\right):$}

It is known as non-compensated elasticity Marshall, which is estimated on the light of changing prices without taking into account the impact on the real income of the consumer and calculated from the following equation:

$$
\boldsymbol{\varepsilon}_{\mathrm{ii}}=\delta_{\mathrm{ii}-}+\frac{\gamma_{\mathrm{ii}}}{\mathrm{W}_{\mathrm{i}}}
$$

Where:

$\delta_{\text {ii }}=1$ if $\mathrm{i}=\mathrm{j}$

$\mathrm{W}_{\mathrm{i}}$ : is the share of the item of expenditure.

$\gamma_{\mathrm{ii}}, \beta_{\mathrm{i}}$ : parameters

2 - Compensated Cross Price Elasticity $\left(\dot{\varepsilon}_{\mathrm{ij}}\right)$ :

It is known as compensated / elasticity Hicks Slutsky, which are estimated on light of changing prices, taking into account the impact on the real income of the consumer and calculated from the following equation:

$$
\dot{\boldsymbol{\varepsilon}}_{\mathrm{ij}}=\delta_{\mathrm{ij}}-\frac{\gamma_{\mathrm{ij}}}{\mathrm{W}_{\mathrm{i}}}-\beta_{\mathrm{i}} \frac{\mathrm{W}_{\mathrm{j}}}{\mathrm{W}_{\mathrm{i}}}
$$

Where: $\delta_{\mathrm{ii}}=$ zero if $\mathrm{i} \# \mathrm{j}$.

\section{3 - Expenditure Elasticity $\left(\boldsymbol{\mu}_{\mathrm{i}}\right)$ :}

Estimated from the following equation:

$$
\mu_{\mathrm{i}}=1+\frac{\beta_{\mathrm{i}}}{\mathrm{W}_{\mathrm{i}}}
$$

Results can be validated ensure the relationship between the weighted elasticity of commodity group as follows:

$$
={ }_{\mathrm{i}=1}^{\mathrm{n}} \mathrm{W}_{\mathrm{i}} \sum \mu_{\mathrm{i}}
$$

Where, the total expenditure elasticizes of the total value of expenditure on commodity group were equal to one.

\section{Research results and discussion}

The method of estimating the Almost Ideal Demand System (AIDS):

To estimate the parameters of (AIDS) during the period (1990-2013) is configured to three equations which represents the dependent variable expenditure scale for groups of red meat, fish and poultry. Whereas the independent variables are the price of red meat, fish and poultry, and the total expenditure on meat group on the algorithm case, the following methods has been using to estimate the model parameters difference, between them namely:

\footnotetext{
- Seemingly Unrelated Regression (SUR)

- Three Stage Least Square (3SLS)

- Generalized Method of Moments (GMM)
} 
By comparing the results of these methods, the three aforementioned shows that: the method is used Generalized Method of Moments (GMM), one of the best ways to estimate the equations of real-time demand model parameters at one time, where the information is used Full Information Methods included in the equations of model estimate when estimating any equation, in addition to that she gave an unbiased, consistent and efficient estimates, which take this approach address the disparity between random variables in the various model equations appreciation of the time series of data used in the estimate. So it has been relying on the results of the assessment of the landmarks equations optimal application form (AIDS) by this method, the quality of results of the assessment by (SUR) (Seemingly Unrelated Regression), or method of (Three Stage Least Square ) (3SLS).

First: the most important economic indicators for the function demand for meat group during the period (1990-2013):

This section aims appreciation standard optimal demand for red meat in Egypt during the period (1990-2013) using the optimal application Almost model Ideal Demand System (AIDS), in a way (Zellner), based on Stones Stone Price Index, it was also used the Hausman Specification Test, to determine the optimal quality model estimate the demand for red meat in Egypt characterization.

Where A review of Table (2) that the average spending on goods that are the subject during the period (1990 to 2013) was about 27.8 and about 11.4 and about 8 million pounds of red meat, fish and poultry, respectively, where the consumer share amounted to spending on red meat, fish and poultry respectively about 0.588 and about 0.242 and about 0.170 of the average total expenditure on meat of a total of about 47.26 million pounds during the period of study and research..

A review of results table (3) that the value of the coefficient of determination to model the demand for red meat in Egypt amounted to about 0.384, and this shows that changes in red meat, fish and poultry prices, and total consumer spending explain about $38.5 \%$ of the changes in the proportion of spending on red meat and the rest of the changes are due to other factors.

It was found that there is a direct correlation between the price of red meat and the proportion of spending on them, and this shows that the increase in the price of red meat by one pounds per $\mathrm{kg}$ leads to increase the proportion of spending by about 0.2614 pounds, assuming all other factors stability at a certain level.

While it is showing an inverse relationship between the price of fish and the spending on red meat as an increase in the proportion of fish rate by one pound to $\mathrm{kg}$ leads to lower spending on red meat at about 0.23 pounds. While it is showing an inverse relationship between the price of poultry and between spending on red meat as an increase in the proportion of poultry rate by one pound to $\mathrm{kg}$ leads to lower spending on red meat at about 0.0729 pounds, assuming all other factors stability at a certain level.
As it turns out that there is a direct correlation between total consumer spending on meat group and the percentage of consumer spending on red meat, which shows that the increase in total consumer spending on meat by one pounds per $\mathrm{kg}$ lead to increased consumer spending on red meat at about 0.1222 pounds per $\mathrm{kg}$.

Results of price demand elasticity's for red meat has shown -table (4) that any change in red meat prices by $10 \%$ leads to lower spending on red meat by 6.8 percent and assuming all other factors stability at a certain level. Therefore, the demand for red meat is considered inelastic, as the relative change in spending on red meat less than the relative change in prices of red meat ratio.

Cross Elasticity's demand also indicate -table (4) that a change in the fish price by $10 \%$ leads to lower spending on red meat $4.41 \%$ rate and therefore the relationship between red meat and fish are complementary relationship, where that relationship counterproductive between the relative change in price spending on fish and red meat. While it is showing that a change in the price of poultry by $10 \%$ leads to lower spending on red meat ratio by $1.6 \%$ and therefore the relationship between red meat and poultry is a complementary relationship, where that relationship counterproductive between the relative change in the price of poultry and spending on red meat.

Flexibility on the spending power of red meat also indicate that a change in the total consumer spending on meat group by $10 \%$ leading to increased spending on red meat ratio of $12.1 \%$ and assuming all other factors stability at a certain level. This shows that red meat is a commodity and that means that the more consumer income spent, the more the ratio has increased to such item is greater than the rate of increase in the rate of income.

\section{1- Demand for fish function:}

A review of results table (3) that the value of the coefficient of determination to model the demand for fish in Egypt amounted to about 0.825 , and this shows that changes in red meat, fish and poultry prices, and total consumer spending explain about $82.5 \%$ of the changes in spending on fish ratio The rest of the changes are due to other factors.

There is an inverse relationship between the price of red meat and fish between spending ratio has been shown as an increase in the price of red meat by one pound to $\mathrm{kg}$ leads to lower spending on fish at about 0.23 pounds.

While it is showing a positive relationship between the price of fish and the proportion of spending on them, and this shows that the increase in the price of fish increased by one pound to $\mathrm{kg}$ leads to increase the proportion of spending by about 0.144 pounds, assuming all other factors stability at a certain level.

While it is showing a positive relationship between the price of poultry and fish between the spending rates as an increase in price of poultry by one pound per $\mathrm{kg}$ lead to increased spending on fish around 0.1006 pounds, assuming all other factors stability at a certain level.

As it turns out that there is an inverse relationship between total consumer spending on meat group and the percentage of consumer spending on fish, which shows that the increase in total consumer spending on meat by one pound 
to $\mathrm{kg}$ leads to lower consumer spending on fish ratio of about 0.1458 pounds per $\mathrm{kg}$.

Results of price demand elasticity's for fish has shown that any change in the price of fish increased by $10 \%$ leads to lower spending on fish by 2.58 percent and assuming the stability of the rest of the other factors at a particular level. Therefore, the demand for fish is considered inelastic, as the relative change in spending on fish less than the relative change in the price of fish - ratio table (4).

Cross Elasticity's demand also indicate - that a change in red meat prices by $10 \%$ leads to lower spending on fish by 6.0 percent, so the relationship between red meat and fish are complementary relationship, where that relationship counterproductive between the relative change in the red meat price and spending on fish. While the change in the prices of poultry by $10 \%$ leading to increased spending on fish ratio of $3.1 \%$, and therefore the relationship between poultry and fish is a reciprocal relationship, where that relationship proportional between the relative change in the price of poultry and spending on fish - table (4).

Flexibility also indicate spending power on the fish that a change in the total consumer spending on meat group by $10 \%$ leads to increase the proportion of spending on fish by $4.0 \%$ and assuming all other factors stability at a certain level. This shows that the fish are essential commodity This means that the more consumer income, the lower the percentage spent on that item has increased at a rate less than the rate of increase in income.

\section{2- Demand for chicken function:}

A review of results table (3) that the value of the coefficient of determination to model the demand for poultry in Egypt amounted to about 0.725, and this shows that changes in red meat, fish and poultry prices, and total consumer spending explain about $72.5 \%$ of the changes in spending on poultry ratio The rest of the changes are due to other factors.

Show an inverse relationship between the price of red meat and poultry between spending rate has been shown as an increase in the price of red meat by one pound to $\mathrm{kg}$ leads to lower spending on poultry by about 0.073 .

As it turns out there is a direct correlation between the price of fish and the proportion of spending on poultry as an increase in the price of fish increased by one pound to $\mathrm{kg}$ lead to increased spending on poultry around 0.1006 assuming all other factors stability at a certain level.

While having an inverse relationship between the price of poultry and the proportion of spending on them, and this shows that the increase in price of poultry by one $\mathrm{kg}$ pounds of lead to the low rate of spending by about 0.1998 pounds, assuming all other factors stability at a certain level.

As it turns out that there is a direct correlation between total consumer spending on meat group and the percentage of consumer spending on poultry, which shows that the increase in total consumer spending on meat by one pounds per $\mathrm{kg}$ lead to increased consumer spending ratio on poultry around 0.0644 pounds per $\mathrm{kg}$.
Results of price demand elasticity's for poultry has shown - that any change in the prices of poultry by $10 \%$ leads to lower spending on poultry by 17.1 percent and assuming all other factors stability at a certain level. Therefore, demand for poultry is flexible, as the relative change in spending is greater than the relative change in the proportion of poultry Provisional price (4).

Cross Elasticity's demand also indicate - that a change in red meat prices by $10 \%$ leads to lower spending on poultry ratio of $6.5 \%$, and therefore the relationship between the poultry and red meat is a complementary relationship, where that relationship counterproductive between the relative changes in prices of red meat and spending Poultry. While the change in the price of fish increased by $10 \%$ leading to increased spending on poultry ratio of $6.82 \%$, and therefore the relationship between poultry and fish is a reciprocal relationship, where that relationship proportional between the relative change in the price of fish and spending on poultry Table (4).

Flexibility also indicate spending power on poultry to the change in the total consumer spending on meat group by $10 \%$ leads to increase the proportion of spending on poultry by $13.8 \%$ and assuming the stability of the rest of the other factors at a particular level. This shows that the poultry are essential commodity This means that the more consumer income spent, the more the ratio has increased to such item is greater than the rate of increase in the rate of income.

Second: The test results verify the terms of a function of the estimated demand models:

Hausman test is uses to detect the presence of correlation between the internal variables in the form of realtime or not, on the basis of Instrumental Variables which expresses the exogenous variables in the model variables on the right side Right Hand Side and variable left side can be a internal variables, then we experience significant transactions If was not significant, it indicates that there is no correlation between them, and then estimated manner (OLS) without the need for real-time estimation in two phases.

It was found from the test quality characterization ADIS model - using the Hausman Specification test stability OLS estimates way to AIDS model. Indicates that the price variables are Endogenous Variables, that is, they are determined equilibrium value through appreciation model where it is predetermined variables.

The results of the greatest probability ratio test LRT to the possibility of counts bases refused to lack of (uniformity or homogeneity), as the value of the larger probability ratio test LRT less than the calculated value of Chi-square $\left(\chi^{2}\right)$ Tabulated at 0:05 moral level. And it has been estimated consumption of red meat in Egypt during the period (19902013) using the optimized application form (AIDS) under the symmetry and harmony together - Table (5). 
Proc. of The Third Intl. Conf. on Advances in Social Science, Management and Human Behaviour - SMHB 2015 Copyright (C) Institute of Research Engineers and Doctors, USA .All rights reserved.

ISBN: 978-1-63248-067-5 doi: 10.15224/ 978-1-63248-067-5-64

\section{Figures and Tables}

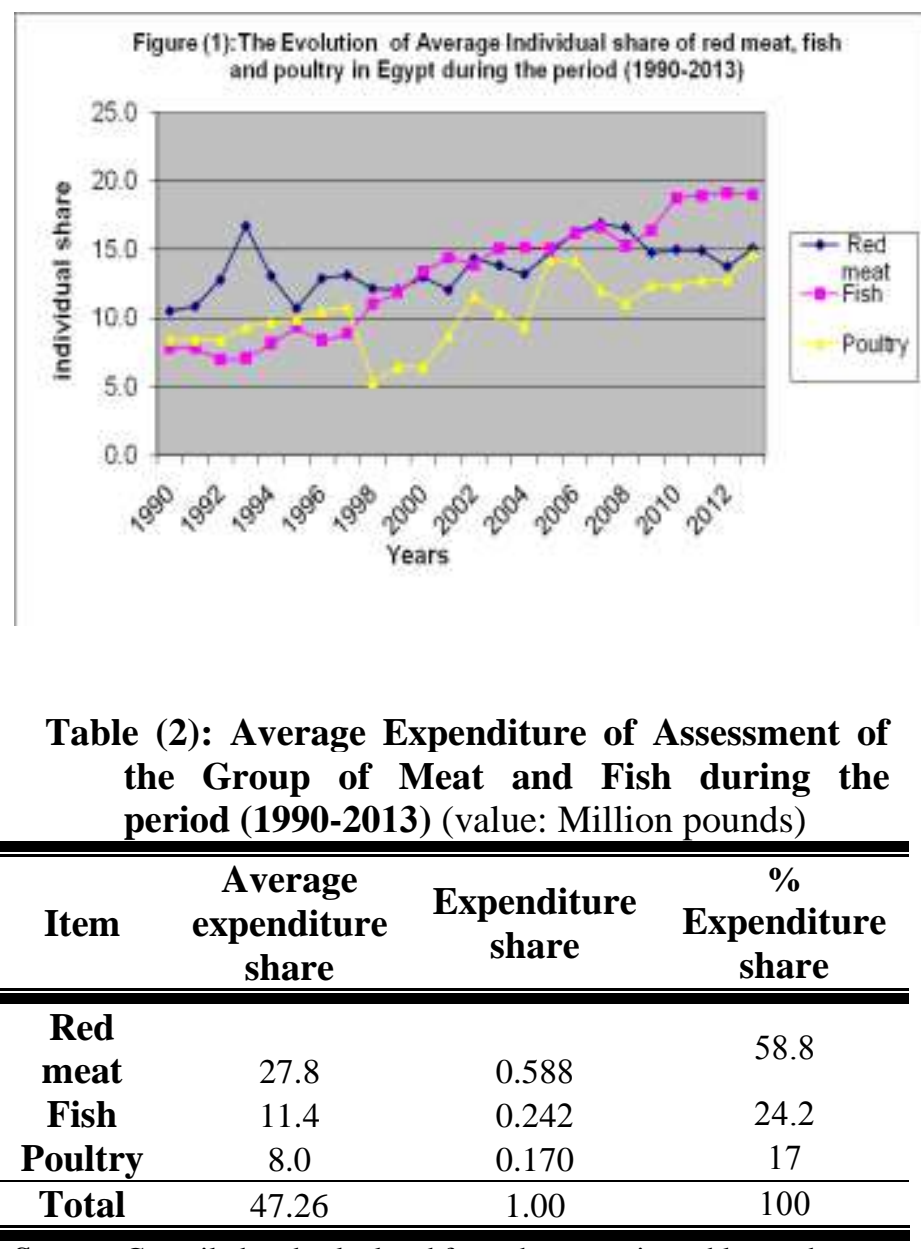

Source: Compiled and calculated from the extension table number

(1) research
Table (1): The average of individual share of red meat, fish and poultry at national level during the period (1990-2013) (kg/year)

\begin{tabular}{|c|c|c|c|}
\hline \multirow{2}{*}{ years } & \multicolumn{3}{|c|}{ Average of individual share } \\
\hline & Red Meat & Fish & Poultry \\
\hline 1990 & 10.5 & 7.8 & 8.5 \\
\hline 1991 & 10.9 & 7.8 & 8.5 \\
\hline 1992 & 12.8 & 7.0 & 8.4 \\
\hline 1993 & 16.8 & 7.1 & 9.4 \\
\hline 1994 & 13.1 & 8.2 & 9.7 \\
\hline 1995 & 10.7 & 9.4 & 10.0 \\
\hline 1996 & 12.9 & 8.4 & 10.6 \\
\hline 1997 & 13.2 & 8.9 & 10.8 \\
\hline 1998 & 12.2 & 11.1 & 5.4 \\
\hline 1999 & 12.1 & 11.9 & 6.5 \\
\hline 2000 & 13.0 & 13.4 & 6.5 \\
\hline 2001 & 12.1 & 14.4 & 8.8 \\
\hline 2002 & 14.4 & 13.9 & 11.6 \\
\hline 2003 & 13.9 & 15.1 & 10.4 \\
\hline 2004 & 13.2 & 15.2 & 9.4 \\
\hline 2005 & 14.8 & 15.1 & 14.2 \\
\hline 2006 & 16.3 & 16.2 & 14.2 \\
\hline 2007 & 16.9 & 16.6 & 12.1 \\
\hline 2008 & 16.6 & 15.3 & 11.1 \\
\hline 2009 & 14.8 & 16.4 & 12.4 \\
\hline 2010 & 15.0 & 18.8 & 12.4 \\
\hline 2011 & 15.0 & 19.0 & 12.8 \\
\hline 2012 & 13.8 & 19.2 & 12.8 \\
\hline 2013 & 15.1 & 19.1 & 14.7 \\
\hline Average & 13.76 & 13.15 & 10.47 \\
\hline b & 0.17 & 0.58 & 0.24 \\
\hline Growth & 1.20 & 4.40 & 2.33 \\
\hline
\end{tabular}

Source: Ministry of Agriculture and Land Reclamation, Economic Affairs Sector, the Central Administration Agrarian economy, The Balance of Food Arab Republic of Egypt, Cairo, number of sporadic.

Table (3): Estimated parameters of (AIDS) ${ }^{+}$to the red meat demand in Egypt during (1990-2013)

\begin{tabular}{cccccc}
\hline \hline Item & $\begin{array}{c}\text { Coefficients of } \\
\text { logarithm } \\
\text { expenditure } \\
\mathbf{B}_{\mathbf{i}}\end{array}$ & \multicolumn{2}{c}{$\begin{array}{c}\text { Coefficients of prices } \\
\text { logarithm }\left(\mathbf{Y}_{\mathbf{i j}}\right)\end{array}$} & $\mathbf{R}^{2}$ \\
\hline \hline Meat & 0.1222 & 0.2614 & -0.2298 & -0.0729 & 0.384 \\
& 1.425 & $5.11^{*}$ & $-6.25^{*}$ & $-2.44^{* *}$ & \\
Fish & -0.1458 & -0.2298 & 0.1442 & 0.1006 & 0.825 \\
& -1.307 & $-6.255^{*}$ & $10.56^{*}$ & $-4.70^{*}$ & \\
Poultry & 0.0644 & -0.0729 & 0.1006 & -0.1998 & 0.725 \\
& $1.899 * *$ & $-2.44^{* *}$ & $-4.70^{*}$ & $7.58^{*}$ & \\
\hline \hline
\end{tabular}

Source: Compiled and calculated from: Appendix (1).

+ Search using the E-views 6.

*Coefficients statistically significant at a significance level 0.05 .

**Coefficients statistically significant at a significance level 0.01 . 
Table (4): Expenditure and price elasticity of the Almost Ideal Demand System (AIDS) at red meat in Egypt during (1990-2013)

\begin{tabular}{|c|c|c|c|c|c|c|c|}
\hline \multirow[t]{2}{*}{ Item } & \multirow{2}{*}{$\begin{array}{c}\text { Expenditure } \\
\text { elasticity } \\
\mathbf{M}_{\mathbf{i}} \\
\end{array}$} & \multicolumn{3}{|c|}{$\begin{array}{l}\text { Own price elasticity- } \\
\text { non Compensated }\left(\mathbf{E}_{\mathrm{ii}}\right)\end{array}$} & \multicolumn{3}{|c|}{$\begin{array}{l}\text { Cross Price elasticity - } \\
\text { Compensated }\left(\mathbf{E}_{\mathrm{ij}}\right)\end{array}$} \\
\hline & & Meat & Fish & Poultry & Meat & Fish & Poultry \\
\hline $\mathbf{M}$ & & 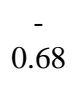 & 0 & 0 & 0 & $0 . \overline{441}$ & -0.159 \\
\hline Fish & 0.40 & 0 & 0.258 & 0 & $\begin{array}{c}0.60 \\
-\end{array}$ & 0 & 0.31 \\
\hline Poultry & 1.38 & 0 & 0 & -1.710 & 0.65 & 0.682 & 0 \\
\hline
\end{tabular}

Source: compiled from: the analysis of research data using the E-views 6 - table (3).

Table (5): Results of test requirements demand function using Almost Ideal Demand System (AIDS) on red meat in Egypt during (1990-2013)

\begin{tabular}{cccc}
\hline \hline AIDS Model & $\begin{array}{c}\text { Logarithm of } \\
\text { probability } \\
\text { function } \\
\text { LK }\end{array}$ & $\begin{array}{c}\text { ratio test } \\
\text { probability }\end{array}$ & $\begin{array}{c}\text { value of } \\
\text { chi } \\
\text { square } \\
\chi^{\mathbf{2}}\end{array}$ \\
\hline \hline $\begin{array}{c}\text { Without condition } \\
\text { With Homogeneity } \\
\begin{array}{c}\text { Condition } \\
\text { With Homogeneity } \\
\text { and Symmetry } \\
\text { Condition }\end{array}\end{array} 2^{245.3}$ & - & - \\
\hline \hline
\end{tabular}

Source: Compiled and calculated from: Results of analysis of research data - reference (1).

\section{Conclusion}

The research aims to estimate the best red meat demand in Egypt during the period (1990-2013) using Almost Ideal Demand System (AIDS), in order to identify the most important variables affecting the red meat based on the prices of red meat, fish and poultry, and analysis of the relationships between them on the light of competition in the percentage of their expenditure

The research using the method (Zellner), used the Stones Price Index.

The results estimating the optimal demand for red meat demand AIDS using the optimal model in the Arab Republic of Egypt during the period has shown (19902013) High percentage of the Egyptian consumer spending on red meat, fish and poultry. Which amounted to about $58.8 \%, 24.2 \% 0.17 \%$, respectively, which means the consumer preference for red meat for fish and poultry in bridging the requirements of the animal protein products.

\section{References}

[1] The website of the Central Agency for Public Mobilization and Statistics www.capmas.gov.eg
[2] Website of the Arab Food and Agricultural Organization www.fao.org

[3] Central Agency for Public Mobilization and Statistics, Monthly Bulletin of the Average Food Prices at the Consumer in the Arab Republic of Egypt, Cairo, the number of sporadic.

Gaber Bassyouni (Dr.),Mamdouh Elbadry (Dr), An Estimating Econometric Study on Citrus with Almost Ideal Demand System (AIDS) and with Inverse Almost Ideal Demand System (IAIDS), The $35^{\text {th }}$ International Conference for Statistics, Computer Science and its applications 11-22 April 2010, Statistical Association and Egyptian Central Agency for Public Mobilization and Statistics.

[5] Gaber Bassyouni, Mamdouh Elbadry " An Estimating Econometric Study to estimate Red Meat Demand using Almost Ideal Demand System (AIDS) in Egypt " Scientific Conference of the Third Livestock Research in the Middle East and North Africa, from 29 to 1 December 2010, Hall of Foreign Relations, Dokki.

Nouran Abd El hamid - The global financial crisis - its causes and its Effects on the Egyptian agricultural foreign trade , Doctorate Thesis, Agriculture Economics dep, Faculty of Agriculture,Mansoura University,2014.

[7] Gaber Bassyouni, Mamdouh Elbadry - An Estimating Econometric Study on citrus with Almost Ideal Demand System (AIDS) and with Inverse Almost Ideal Demand System (IAIDS), International Conference of the thirty-five for Statistics, Computer Science and its Applications, , Statistical Association and Egyptian and the Central Agency for Public Mobilization and Statistics, April 11 to 22, 2010.

About Author (s)

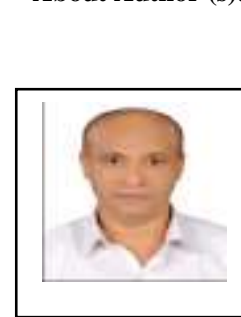

Mamdouh Elbadry was born in Alexandria in 1969. He got his B.Sc. in 1992 at Faculty of agriculture, Alexandria University, and got his M.SC in 1998 and Ph. D. in 2009 at the agriculture Alexandria University. He worked as a Specialist (1995-2011), Research Assistant (2011) in Agricultural Economics Research Institute, Agricultural Research Centre, Egypt, and Researcher (Doctor) (2011-until now). He is a membership of Egyptian Association of Agricultural Economics (Cairo, Egypt). He published many searches in field study and participated in many local and international conferences

Samir Basilious Nakhla was born in Cairo in 1957. He got his B.Sc. in 1983 at Faculty of agriculture Cairo University, and got his M.SC in 1998 and $\mathrm{Ph}$. D. in 2005 at the agriculture Alexandria University. $\mathrm{He}$ worked as a Researcher Assistant (2009) in Agricultural Economics Research Institute, Agricultural Research Centre, Egypt, and Researcher (Doctor) (2009-until now). He is a membership of Egyptian Association of Agricultural Economics (Cairo, Egypt). He published many searches in field study and participated in many local and international conferences

Nouran El Hamid Ibrahim Abd El Gawwad: was born in Mansoura in 1985. She is a lecturer in Faculty of Agricultural, Mansoura University. She got her B.Sc. in 2005 department of Agricultural Economic at Faculty of Agricultural, Mansoura University, and got her M.SC in 2009 and Ph. D. in 2013. She is a membership of Egyptian Association of Agricultural Economics (Cairo, Egypt).

She published many researches in Agricultural Economic and participated in many local and international conferences. 